\title{
Extraction methods and test techniques for detection of vegetable proteins in meat products
}

\section{Qualitative detection of soya derivatives}

\author{
BY N. ST G. HYSLOP \\ Animal Pathology Division, Health of Animals Branch, \\ Agriculture Canada, Animal Diseases Research Institute (E), \\ P.O. Box 11300, Postal Station H, Ottawa, Ontario, Canada, K2H $8 P 9$
}

(Received 28 July 1975)

\section{SUMMARY}

Extracts of 3 soya bean preparations, used commercially in certain countries to replace part of the meat in popular meat products, were made by treatment with (i) sodium dodecyl sulphate, (ii) Triton-X100 or (iii) $n$-Butanol. Similar extracts were made from beef and pork.

All extracts were examined by electrophoretic and immunological techniques. Stained polyacrylamide gels revealed distinctive protein bands after electrophoresis. The migration rates of corresponding bands differed between beef and pork extracts. However, the migration rates of vegetable bands revealed certain similarities, but differed very greatly from those of animal origin. Characteristic fast-migrating S-bands were distinguishable only in extracts of vegetable protein. Immunodiffusion tests, using antisera produced in rabbits against each extract, revealed varying degrees of similarity between extracts of vegetable origin, but the antisera were specific for either vegetable or animal protein.

\section{INTRODUCTION}

During recent years, the rapid increase in the cost of high grade animal proteins, associated with an increased demand for meat, has resulted in the development of numerous 'meat substitutes' which, although derived from vegetable sources, resemble in varying degrees the texture and flavour of meat. At present, the soya bean is the source of protein employed most frequently for this purpose, but the use of other vegetables such as field beans, cotton-seed and wheat gluten is being actively investigated by many manufacturers. Substances of this type are being incorporated in increasing amounts in processed meat products in some countries. Their similarity to animal tissues, when used as additives or 'extenders', is often increased by cooking and extrusion-processing to form filamentous or fibrous masses, known generally as textured vegetable protein (TVP).

The soya bean has been a primary source of protein in the Far East for centuries, and soya flour has been incorporated into food products in the U.S.A. for 50 years. Currently, many countries either prohibit or restrict by specific legislation 
the use of soya proteins in processed meat products. The addition of substances of vegetable origin to meat products is controlled in Great Britain, to some extent, by regulations made under the Food and Drugs Act, 1955 and, particularly, by the Labelling of Food Regulations, 1972. However, eventual harmonization of legislation with practices of the E.E.C. is to be expected. In Canada, regulations under the Food and Drugs Act permit the sale of extended meat products, provided that their protein content is not less than $16 \%$ and provided that their nutritional properties are adequate. In the U.S.A., a proportion up to $3 \frac{1}{2} \%$ soy flour or soy concentrate, but not TVP, is permissible in products such as frankfurters or bologna (J. N. Czarnecki, personal communication). Wherever additions of this type are permitted, there may be a requirement to incorporate a 'tracer', such as titanium dioxide, but this necessitates considerable dependence on the accuracy of formulation and on the integrity of the manufacturer. Various alternative methods of identifying soya bean proteins in meat products have been described; their advantages and disadvantages were reviewed recently (Frouin, 1974).

The following report records the preparation of extracts from soya derivatives or from animal tissues by three methods, and compares their electrophoretic mobilities and immunological characteristics.

\section{MATERIALS AND METHODS}

\section{Soya proteins}

In the present series of experiments, 3 sources of soya protein were examined: (i) soya protein concentrate (S1), (ii) defatted soya flour (S2) and (iii) a TVP 'Promate"III'* (S3). All were in powder or granulated form and so, except for some additional trituration, were not treated further before extraction.

\section{Animal proteins}

With hygienic precautions, small pieces were cut from samples of lean beef muscle. After removal of all visible fat, the pieces were chopped by means of a sterile scalpel blade into cubes of about $0.5 \mathrm{~cm}$. Cubes from several different animals"were pooled and triturated with phosphate buffered $(0.1 \mathrm{M}, \mathrm{pH} 7 \cdot 4)$ saline (PBS) in a Silverson tissue grinder. $\uparrow$ The resultant suspension was centrifuged at $2000 \mathrm{rev} . / \mathrm{min}$. and the supernatant fluid discarded. After a further wash and centrifugation, extracts were made from up to $30 \mathrm{~g}$. of the paste-like deposit. The same procedure was used to prepare pork muscle extract.

\section{Extraction with sodium dodecyl sulphate (SDS)}

Equal amounts ( 5 g.) of each of the vegetable or meat samples were suspended in $50 \mathrm{ml}$. of SDS solution ( $2 \%$ SDS in sterile distilled water, adjusted to $\mathrm{pH} 7 \cdot 0$ ) and comminuted in the Silverson tissue grinder. All suspensions were agitated at room temperature for $6 \mathrm{hr}$., and were then centrifuged at $27,000 \mathrm{~g}$ to deposit any

* Griffith Laboratories Ltd, 757 Pharmacy Avenue, Scarborough, Ontario, Canada.

$\dagger$ Silverson Machines Ltd, 55-57 Tower Bridge Road, London, S.E.1, England. 
undissolved material. The supernatant solutions were cooled at $4^{\circ} \mathrm{C}$., to precipitate most of the SDS and then re-centrifuged in the refrigerated centrifuge. The supernatants were dialysed against several changes of cold isotonic potassium chloride solution and centrifuged again. The last supernatants were placed in a dialysis sac and concentrated to a final volume of $10 \mathrm{ml}$. by immersion in Ficoll powder.

\section{Extraction with Triton-X100* (T-X100)}

The extraction fluid consisted of $0.6 \mathrm{M}$ potassium chloride solution containing $10 \mathrm{~mm}$ histidine, $10 \%$ sucrose and $1 \% \mathrm{~T}$-X100. The freshly prepared fluid was cooled to $4^{\circ} \mathrm{C}$., and all operations were carried out in the coldroom at that temperature. Equal amounts of each vegetable or meat sample (30 g.) were suspended in $300 \mathrm{ml}$. of T-X100, and comminuted in the Silverson grinder for $30 \mathrm{~min}$. on an icebath in the coldroom. The $\mathrm{pH}$ was tested at intervals and adjusted to $\mathrm{pH} \mathrm{7 \cdot 0-7 \cdot 2}$ whenever necessary. Suspensions were shaken for $18 \mathrm{hr}$. and then centrifuged in the refrigerated centrifuge at $27,000 \mathrm{~g}$. The deposits were re-triturated and extracted again with T-X100. Supernatants were pooled from successive extractions, dialysed against PBS and then concentrated by Ficoll.

\section{Extraction with $n$-Butanol $(n B)$}

Equal amounts of each sample of powdered vegetable protein or meat paste $\left(20 \mathrm{~g}\right.$.) were suspended in $180 \mathrm{ml}$. of pre-cooled distilled water and agitated at $0^{\circ} \mathrm{C}$. During agitation, $150 \mathrm{ml}$. of cold $\mathrm{nB}$ was added, and the mixture was transferred to a Silverson container immersed in an ice bath. Trituration was interrupted to allow full cooling by the ice, and the total trituration time was restricted to $20 \mathrm{~min}$. The preparation was then centrifuged for $5 \mathrm{~min}$ at $27,000 \mathrm{~g}$ in the refrigerated centrifuge, and the aqueous layer lying between the deposit and the upper layer (butanol + lipid) was carefully withdrawn. This layer was dialysed in the coldroom for $48 \mathrm{hr}$. at $0-4^{\circ} \mathrm{C}$., to remove any traces of $\mathrm{nB}$, before being concentrated by the Ficoll method at the same temperature.

\section{Electrophoresis of extracts}

The relative migration rates of protein fractions in the various extracts were determined by side-by-side electrophoresis in polyacrylamide gel slabs, using the method described recently for studies on sera from different animal species (Hyslop, 1972). Electrophoresis was carried out in the coldroom and was allowed to continue until experience from trial runs indicated that the fastest moving bands of vegetable protein were approaching the bottom of the slabs. After removal from the apparatus, gels were fixed in acetic acid solution, stained with amido black, and then destained either in acetic acid or electrophoretically. Some of the slabs were restained in Coomassie blue and destained in acetic acid to enhance the density of certain bands for photography.

* Calbiochem Inc., San Diego, California 92112, U.S.A. Lot 200837. 
Table 1. Regimen of immunization with vegetable or animal protein extracts

\begin{tabular}{|c|c|c|c|c|}
\hline Day & Adjuvant type & $\begin{array}{l}\text { Adjuvant } \\
\text { vol (ml.) }\end{array}$ & $\begin{array}{c}\text { Antigen } \\
\text { vol. (ml.) }\end{array}$ & Route of inoculation \\
\hline 1 & None & - & $1 \cdot 0$ & Intradermally into footpads \\
\hline 4 & $\begin{array}{l}7.5 \times 10^{9.0} \text { killed } \\
\text { B. pertussis in phase } 1\end{array}$ & 0.5 & $1 \cdot 5$ & Intraperitoneally \\
\hline 42 & Freund's complete & $1 \cdot 0$ & $1 \cdot 0$ & Subcutaneously - 5 sites \\
\hline 56 & Freund's incomplete & $1 \cdot 0$ & $1 \cdot 0$ & Subcutaneously - 6 sites \\
\hline 84 & Freund's incomplete & $1 \cdot 0$ & $1 \cdot 0$ & Subcutaneously - 6 sites \\
\hline 108 & None & - & $1 \cdot 0$ & Intraperitoneally \\
\hline
\end{tabular}

\section{Immunization of rabbits}

After a quarantine period, young adult female albino rabbits were inoculated with extracts in accordance with the regimen shown in Table 1. Responses of individual rabbits to each extract were monitored by immuno-diffusion tests on serum samples collected at intervals.

\section{Immunodiffusion tests}

To determine the progress of immunization and finally to establish optimal proportions of antigen and antibody, micro-immunodiffusion tests were set up in agar or agarose gels containing dextran (Hyslop, 1973). Antisera from the rabbits were then tested concurrently in agar and agarose gels against the vegetable or meat antigens of each extract, optimal dilutions being used for the homologous reactants. The weaker arcs of the heterologous vegetable antigen-antibody reactions were enhanced by treatment of the gel with $6 \%$ solutions of Dextran (MW 500,000) as described recently (Hyslop \& Cochrane, 1974). Precipitation arcs were stained in Ponceau S, the gels were decolorized, and then dried for storage or for photography.

\section{Electrophoresis}

\section{RESULTS}

The relative electrophoretic mobility of each of the protein fractions from the three soya products and from the tissue samples of beef and pork, solubilized by the three extractants, are demonstrated in Plate 1. It will be noted that protein bands from beef and pork differed from each other and differed also from bands of vegetable origin. However, the migration rates of proteins of vegetable origin revealed close similarities although, depending on the starting material and on the extraction method used, quantitative differences were apparent in the intensity with which corresponding bands bound the stain. It is significant that all the extracts from soya products (S1, S2 and S3) contained low molecular weight material which produced fast-migrating bands during electrophoresis in polyacrylamide gels. Similar bands were not demonstrable in extracts of animal tissues prepared by the same process.

The fast-moving bands were designated ' $S$ ' bands (Plate 1 ), and have been 
detected in varying concentration in all soya products tested up to the present time, including combinations of meat and vegetable proteins prepared in various proportions to simulate commercially-processed products.

\section{Immunological reactions}

When the immunization regimen was terminated, preliminary tests to establish the optimal dilutions of homologous antigen-antibody combinations revealed that, in addition to marked variation in the ability of individual rabbits to react to the same antigens, differences occurred in the ability of groups of rabbits to respond to different antigens. In particular, the heat-treated S3 (TVP) evoked an inferior response irrespective of the extraction method used. This was probably associated with denaturation by heat during manufacture. Immunodiffusion tests employing optimal values for the homologous antigen-antibody combinations generally revealed multiple arcs of precipitation, although only a single faint arc was detectable with S3. In heterologous combinations (e.g. in Plate 2) it was apparent that, although arcs common to all the vegetable extracts were present, there was also some spur formation indicative of the existence of additional antigens which were not common to all extracts. Similar common arcs and spurring were observed when antisera against each vegetable extract were tested against homologous and heterologous vegetable extracts.

However, it is significant that none of the antisera prepared from vegetable extracts showed any reaction with the meat extracts.

The rabbit antibody, prepared from pork extracted by $\mathrm{nB}$, produced a strong arc during immunodiffusion against the homologous antigen and a slight crossreaction, with marked spur formation, against the beef antigen extracted by the same method. All the antisera prepared against beef extracts reacted only with the beef antigen. Neither pork nor beef antisera reacted with any of the vegetable antigens. The sera of 6 rabbits, which received only inoculations of saline were devoid of reactivity with any of the extracts.

\section{DISCUSSION}

In preliminary experiments attempts to extract protein by cold or warm aqueous solution, by normal saline or by simple buffers failed to yield amounts of soluble material adequate for electrophoresis or for immunological tests.

The anionic detergent SDS has been used widely as a 'solubilizing agent', though it may cause denaturation of certain proteins. Nevertheless, it has been used for extracting the virus of foot and mouth disease at concentrations up to $5.0 \%$ without damage to the immunogenic structure of the virus (Cartwright \& Thorne, 1958). Numerous authors have incorporated SDS in acrylamide gels, with the result that electrophoresis separates the negatively charged protein-SDS micelles almost entirely according to their MW (Shapiro, Vinuela \& Maizel, 1967; Balant, Mulli \& Fabre, 1974). However, to permit direct comparison of all extraction methods within the same gel slab, SDS was used solely for extraction of the 
protein, and was removed from the extract by cold precipitation, with subsequent precipitation of any residual traces of SDS by dialysis against $\mathrm{KCl}$ solutions.

The non-ionic detergent Triton-X100 was particularly effective in extracting protein from material of both animal and vegetable origin. Detergents of this type may extract up to $99 \%$ of animal proteins (Bjerrum \& Lindahl, 1974). The precipitation arcs obtained with T-X100 (Plate 2) indicated that the immunogenic properties of T-X100 extracts from unheated soya products or meat were satisfactory, and supported previous observations on the action of non-ionic detergents on cell membrane proteins. In our hands a concentration of $1 \% \mathrm{~T}$-X100 gave better results than $0.5 \%$. Nevertheless, the SDS preparation appeared to extract the greatest amount of antigenic material from some, but not all, samples of the heat-treated soya product S3.

At the concentration used, $\mathrm{nB}$ was not particularly effective in extracting protein either for electrophoretic analysis or for use as antigen, but it was of interest to note that different 'solubilizing agents' either extracted different amounts of band-forming material or conferred different migratory properties on them.

After processing, it was desirable to store extracts at $4^{\circ} \mathrm{C}$., because early experiments demonstrated that, when frozen, the protein solutions tended to become unstable and to form precipitates which could be re-dissolved again only with some difficulty.

The protein band formation in the electrophoresis gels, and especially the presence of S-bands, provided a good indication of the source of the protein. In mixtures of soya and meat protein prepared to simulate commercial products, the presence of soya protein remained detectable until the concentration of soya extract was reduced to the extent that the characteristic bands could not be stained sufficiently deeply to be identified ( $<2 \%$ vegetable matter). The range of vegetable sources in addition to the soya bean, from which S-band proteins may be extracted remains to be determined. However, the demonstration of S-bands provides a strong indication of vegetable origin.

Although the meat samples possibly contained slight traces of residual plasmaproteins, neither the meat nor the vegetable extracts proved to be highly potent antigens. Consequently, the rabbits required a fairly prolonged course of immunizing inoculations. The vegetable extracts were mildly toxic to rabbits, and attempts to stimulate antibody production by intravenous inoculation evoked signs of severe shock, even in unprimed rabbits. Multiple arcs of precipitation during immunodiffusion tests of the S1, S2 and S3 extracts revealed both shared and unique antigenic components in the different vegetable extracts, but no cross reactivity with meat extracts was detected either in tests using S1, S2 and S3 or in tests using similar soya products obtained from another manufacturer. The arcs developing between S3 and homologous antisera, or antisera prepared from other soya extracts, were often relatively weak and were difficult to record photographically, but, having regard to the manufacturing processes used to produce TVP (which usually include high temperature extrusion methods), perhaps it is remarkable that any characteristic antigenic properties remained. 
The nutritional value of suitably treated vegetable protein may be adequate, and palatability remains satisfactory if the concentration of the vegetable protein is not too great. However, the incorporation of excessive amounts of vegetable protein, even of the textured form derived from soya beans, tends to be selflimiting to some extent, because changes in flavour and texture eventually become apparent. The highest concentrations of vegetable additives may be found in wiener sausage and similar highly flavoured formulations, in which the constituents are first emulsified and cooked. For products of this type, tests which depend on the histological identification of vegetable cells may be expected to give the least accurate results.

The U.S. Department of Agriculture predicted that by about 1980 soya substitutes will replace about $10-20 \%$ of all meat consumed by human beings, and it has been suggested that at that time $25-50 \%$ of all ground meat products will contain TVP as an additive (Wilding, 1974). It is evident that a variety of economic, productivity and distributional factors will compel the rapidly expanding world populations, and especially those of the more technologically advanced 'meat-eating' countries, to accept the fact that an increasing proportion of their protein intake must be derived from, or mixed with, proteins of vegetable origin. However, it is particularly important that consumers shall be protected from undisclosed incorporation of considerable amounts of textured, but relatively inexpensive, vegetable material into expensive meat products. Furthermore, in addition to considerations of cost, it is essential that digestibility and nutritional value of the vegetable substitutes shall approximate, as closely as possible, to those of meat. For these reasons the development of reliable and rapid methods for identification of vegetable matter in processed meat products is highly desirable.

The author wishes to thank Mr G. Goyette and Mr R. Gorman for their valuable assistance. Photographic material and illustrations were prepared by the Graphics Unit, Agriculture Canada.

\section{REFERENCES}

Batant, L., MULLI, J. C. \& FABRE, J. (1974). Urinary protein analysis with sodium dodecyl sulphate-polyacrylamide gel electrophoresis. Clinica chimica acta 54, 27-37.

BJERRUM, O. J. \& LINDAHL, P. (1974). Crossed immunoelectrophoresis of human erythrocyte membrane proteins. Biochimica et biophysica acta 342, 69-80.

Cartwright, Sheila F. \& Thorne, H. V. (1958). Some applications of detergents to the study of the virus of foot and mouth disease. Journal of General Microbiology 20, 61-77.

Frourn, A. (1974). Detection of soy proteins. Journal of the American Oil Chemists' Society 51, $188 \mathrm{~A}-89 \mathrm{~A}$.

Hyslop, N. St G. (1972). Application of an improved system of electrophoresis in acrylamide gel to studies on the sera of different species. Journal of Clinical Pathology 25, 508-11.

HYSLOP, N. ST G. (1973). Effect of dextrans of different mean molecular weights on immunodiffusion reactions of serum fractions. Journal of Chromatography 77, 445-9.

Hyslop, N. St G. \& Cochrane, Delma G. (1974). Effects of dextrans on immunoprecipitation in agar and in low-temperature-gelling agarose gels. Journal of Immunological Methods 6, 99-107.

Shapiro, A. L., Vinuela, E. \& Maizel, J. V. (1967). Molecular weight estimation of polypeptide chains by electrophoresis in SDS-polyacrylamide gels. Biochemical and Biophysical Research Communications 28, 815-20.

Wilding, M. S. (1974). Textured proteins in meats and meat-like products. Journal of the American Oil Chemists' Society 51, 128A-30A. 


\section{EXPLANATION OF PLATES}

\section{Plate 1}

Electrophoretic mobilities of vegetable and meat extracts in polyacrylamide gels. $\rightarrow$, ' $S$ ' bands; S1, soya bean concentrate; S2, defatted soya flour; S3, textured vegetable protein; B, beef; $\mathrm{P}$, pork; ..., faint band (not readily reproducible in print).

\section{Plate 2}

Immunologic relationships of vegetable extracts and their non-identity with meat extracts. Peripheral wells, antigens; central wells antisera. C, saline control; S1, soya bean concentrate; S2, defatted soya flour; S3, textured vegetable protein; B, beef; P, pork. 
Extraction method

SDS

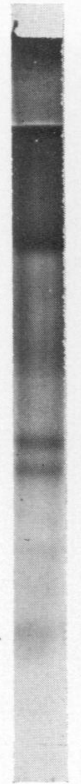

S1
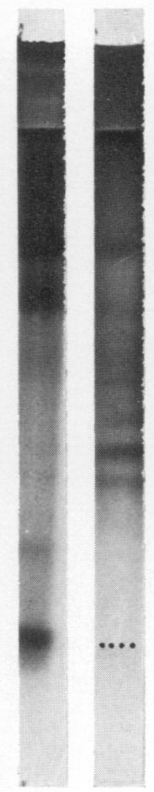

S3
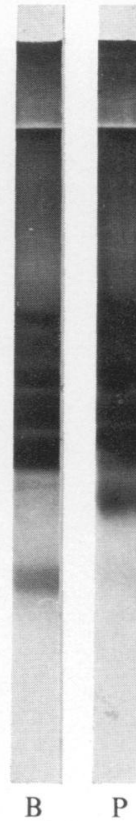

Triton-X100

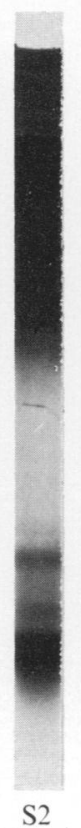

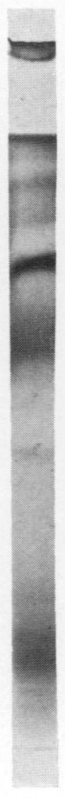

S3

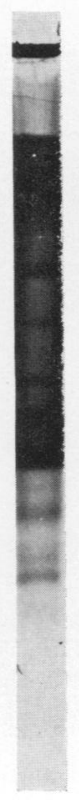

B

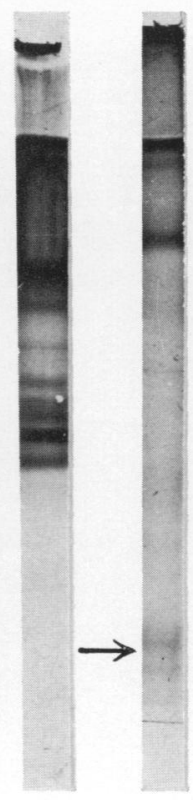

S1 n-butanol

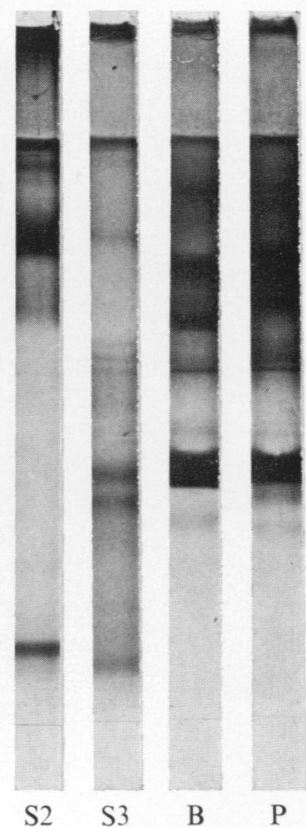


SDS extract

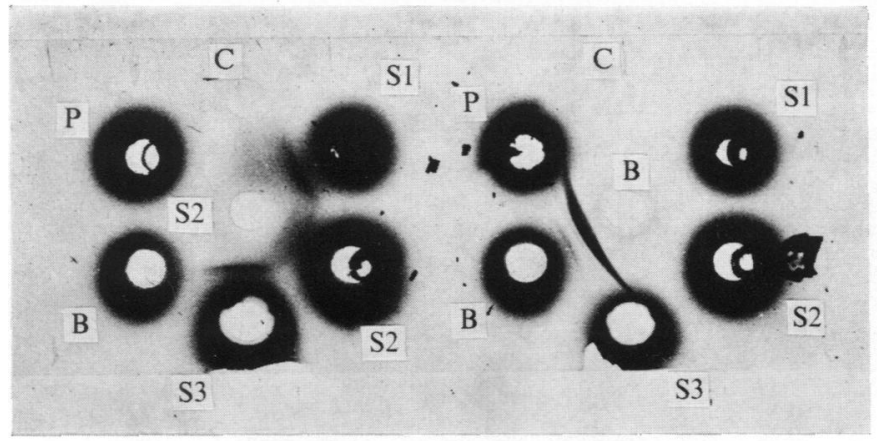

Triton-X100 extract

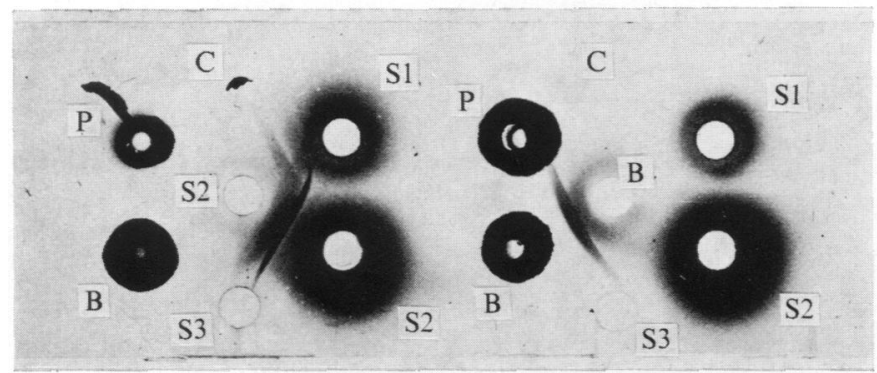

$n$-butanol extract

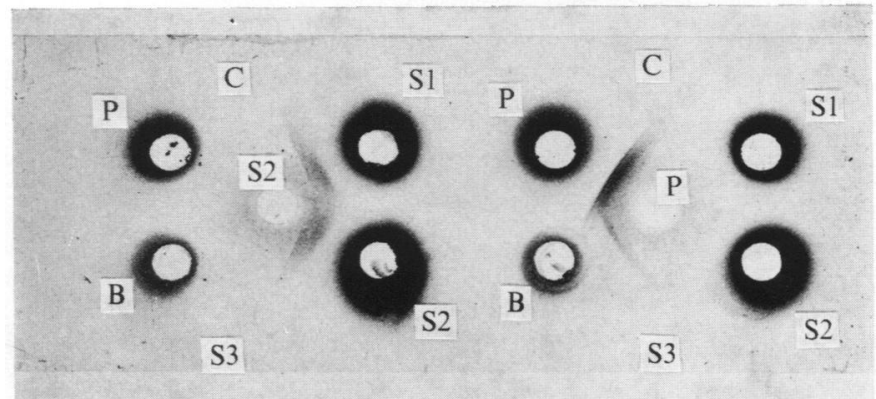

